\title{
O CONCEITO DE FILOSOFIA DO DIREITO E A TRANSFORMAÇÃO SOCIAL EM ALYSSON MASCARO
}

RESUMO: O presente trabalho objetiva introduzir o pensamento crítico de Alysson Mascaro, por meio dos conceitos de filosofia e filosofia do direito que o autor sintetiza na obra Filosofia do Direito. Com a metodologia qualitativa, de análise bibliográfica, a pesquisa aborda as reflexões sobre a relação complexa existente entre o pensamento filosófico e a materialidade social, e por sua vez, a filosofia do direito como ferramenta conceitual teórica capaz de denunciar a forma-jurídica como legitimadora da reprodução capitalista. A filosofia, tal como uma árvore, possui suas raízes fincadas na tradição histórica com distintos métodos e diversos ramos, entre os ramos, está a filosofia do direito. Destaca-se a tradição marxista como caminho mais alto para pensar o direito e as suas contradições estruturais advindas da transição do feudalismo para a modernidade burguesa. Mascaro apresenta através das categorias marxistas, o desenvolvimento da filosofia do direito crítica na contemporaneidade, que constrói novos horizontes revolucionários para promover, estruturalmente, a transformação social.

Palavras-chave: Filosofia. Filosofia do Direito Contemporânea. Jusfilosofias Críticas.

\section{THE CONCEPT OF THE PHILOSOPHY OF LAW AND SOCIAL TRANSFORMATION IN ALYSSON MASCARO}

\begin{abstract}
The present work aims to introduce the critical thinking of Alysson Mascaro, through the concepts of philosophy and philosophy of law that the author synthesizes in the work Philosophy of Law. With the qualitative methodology of bibliographic analysis, the research addresses reflections on the complex relationship between philosophical thought and social materiality, and in turn, the philosophy of law as a theoretical conceptual tool capable of denouncing the legal-form as legitimizing of capitalist reproduction. Philosophy, like a tree, has its roots in the historical tradition with different methods and different branches, among the branches is the philosophy of law. The Marxist tradition stands out as the highest way to think about law and its structural contradictions arising from the transition from feudalism to bourgeois modernity. Mascaro presents, through the Marxist categories, the development of the philosophy of critical law in contemporaneity, which builds new revolutionary horizons to structurally promote social transformation.
\end{abstract}

\footnotetext{
${ }^{1}$ Acadêmico de Direito da Universidade Estadual do Oeste do Paraná (UNIOESTE), membro dos Grupos de Pesquisas Corpo, Gênero e Diversidade, e do Observatório Leão XIII de Estudos em Direito do Trabalho e Seguridade Social da Unioeste/FB. Membro do Grupo de Pesquisa Direitos Humanos e Cidadania da Universidade Comunitária da Região de Chapecó (UNOCHAPECÓ). Já foi monitor da disciplina Introdução à Filosofia e participou de vários projetos de extensão da Universidade Estadual do Oeste do Paraná (UNIOESTE). Realiza pesquisas científicas e estudos na área de Filosofia do Direito, especialmente sobre as Filosofias do Direito Críticas. E-mail: guilhermebaggiocosta@hotmail.com
} 
KEY-WORDS: Philosophy. Contemporary Philosophy of Law. Critical Philosophies.

\section{INTRODUÇÃO}

A filosofia e a materialidade social possuem uma relação de pensar o mundo e ser determinado por ele, de tal maneira que existem várias filosofias em cada processo histórico e o seu respectivo modo de produção. Na contemporaneidade, a filosofia do direito crítica de Mascaro (2019a) estabelece nexos conceituais e teóricos sobre o direito e o capitalismo. Nesse artigo, é trabalhado especificamente o conceito de filosofia e posteriormente, a filosofia do direito e a possibilidade de transformação social pelo pensamento filosófico.

Justifica-se a pesquisa pelo método teórico radical da jusfilosofia crítica de Mascaro (2019a), na contramão da maioria dos jusfilósofos, que se inserem nas tradições juspositivistas. Nesse sentido, o pensamento de Mascaro (2019a) oferece ferramentas para transformar a realidade socioeconômica, partindo de críticas estruturais ao direito, em desacordo com o conservadorismo e reacionarismo do jurídico frente às desigualdades no capitalismo.

No contexto do pós-fordismo, assentado politicamente no neoliberalismo, surgido em 1970, no qual há uma coexistência estrutural entre o regime de acumulação e o modo de regulação, pensar criticamente a forma-jurídica é um trabalho complexo que Mascaro (2019a) realiza exiguamente. As obras de Mascaro (2008; 2013; 2018; 2019a; 2019b) escritas no século XXI, no Brasil, possuem entre alguns contextos o golpe jurídicopolítico de 2016 que retirou a ex-presidente Dilma Rousseff, o avanço de políticas econômicas neoliberais, a precarização do trabalho, a retirada de direitos e o aumento da exclusão social de determinados grupos minoritários hegemonicamente.

Com o método dialético, metodologia qualitativa e bibliográfica, inicialmente, será exposto uma tentativa de resposta a partir de Mascaro (2019a), para o questionamento $O$ que é a filosofia? Mascaro (2019a) longe de dar respostas prontas e fáceis, tateia a tradição histórica da filosofia, os atravessamentos dos assuntos, os métodos singulares de cada pensamento e os efeitos políticos das escolhas epistemológicas da filosofia, seja para manter a dominação econômica e social ou para combater a desigualdade social. 
No segundo momento, será demonstrada a conceituação de Mascaro (2019a) sobre a filosofia do direito ao compreendê-la como o atrito entre a tradição histórica da filosofia e o direito, este entendido como assunto ou tema da filosofia geral. A filosofia do direito será vista como o pensamento mais alto sobre o direito, desapegado da mera tecnicidade da Teoria Geral do Direito. A exposição jusfilosófica a ser construída é desenhada pela tradição marxista, que conforme Mascaro (2019a), é a mais profunda reflexão e representa o salto qualitativo no pensamento jurídico. A criticidade será cultivada no texto ao considerar as relações sociais capitalistas e a utilização da formajurídica para a reprodução dessa sociabilidade.

Embora, não seja o objetivo do texto esmiuçar todas as obras de Mascaro (2008; 2013; 2018; 2019a; 2019b), busca-se se debruçar apenas aos conceitos preliminares apresentados na obra Filosofia do Direito. Ressalta-se que por finalidade didática, serão utilizadas as expressões árvore, referindo-se a filosofia geral, e ramo para a filosofia do direito. Essa analogia se deve a defesa de Mascaro (2019a) que a filosofia do direito é apenas um assunto da filosofia, no qual não está separado da sua história, ao contrário, utiliza da sua tradição do passado, seus métodos para pensar o direito.

\section{A ÁRVORE CHAMADA FILOSOFIA}

Inicialmente, é necessário se preocupar com o conceito de filosofia, e para isso, Chaui (2011), escreve que a filosofia é racional e inútil, contudo, a sua inutilidade não diminui a sua importância, pois seu pensamento crítico é considerado inútil para a ordem capitalista que ama a técnica, a filosofia pode não se submeter as ordens mercantis e de exploração. Para Chaui (2011), a filosofia dá possibilidade de não aceitar as coisas como indiscutíveis, como amiga ou amante do saber, reflete o mundo e costura condições de possibilidade de transformação. A filosofia descrita como árvore tem como finalidade didática, compreender que a filosofia do direito é um tema, assunto da filosofia geral, nem mais e nem menos importante que as outras, como a estética, a política, a lógica etc.

Antes de se debruçar sobre a filosofia do direito e a sua relação com a materialidade, é necessário conceituar por esse viés o que seja a filosofia. No capítulo Sobre a Filosofia, Mascaro (2019a) questiona, principalmente, o que pode ser considerado como filosofia, e demonstra as múltiplas respostas construídas pelos/as filósofos/as. Para 
compreender o que é a filosofia, deve-se olhar para a sua historicidade. A filosofia se forma, transforma e se constitui de várias e distintas formas, atravessados pelos modos de produção do processo histórico.

Escreve-se que a filosofia é marcada pela tradição, ou seja, existe filosofia nas Idades Antiga, Medieval, Moderna e Contemporânea. Mascaro (2019a) indaga: O que é a Filosofia do Direito? O que pensaram os/as filósofos/as do direito?

Os caminhos para responder a problemática está para além do filósofo do direito. Inicialmente, para a pergunta sobre o que é a filosofia? Há uma primeira resposta para alguns, no qual a filosofia é o mais alto saber sobre o conhecimento. A resposta é boa, porém problemática, pois como se sabe qual o pensamento mais alto? Aqui está envolvido um critério de acepção valorativa que difere o pensamento filosófico do senso comum. Contudo, essa valoração é política, social e histórica. Acrescenta-se que envolvido pelo caráter valorativo, o critério de avaliação perpassa moralidades, imaginários, concepções e preconceitos que caracterizam cada tempo, tornando a resposta problemática e insuficiente (MASCARO, 2019a).

Outra reflexão importante trazida por Mascaro (2019a) é se a filosofia é a favor ou contra o seu tempo histórico. A observação mais plausível é de que houve ambas as filosofias. Por exemplo, Sócrates foi um filósofo contra o seu tempo, e foi morto pelos poderosos da época. Em outro sentido, Agostinho foi a favor do seu tempo, sem uma concepção transformadora no final da Idade Antiga e início da Idade Medieval, e diferentemente de Sócrates, não foi morto ou perseguido, mas sim, santificado. Para Agostinho as desigualdades entre as classes sociais derivavam da providência divina, por isso seus escritos contribuíram para a manutenção das assimetrias socioeconômicas. A aceitação no campo jurídico e na sociedade de determinado/a filósofo/a não é sinônimo de qualidade em termos de construção filosófica (MASCARO, 2019a).

Existem acepções variadas de filosofia, muitas vezes é reduzido à separação etimológica, como: filo (amizade/amor) sofia (saber): "ama a verdade", "ama o saber". Porém, devemos transcender essa resposta, pois como sei que alguém ama e o outro não ama o saber? Sócrates dizia em seu tempo, que aqueles que vendiam o conhecimento para os ricos, comprometidos com os interesses da guerra não eram filósofos, isso não era amor ao saber, em razão do saber não visar o dinheiro ou lucro. O/a filósofo/a não vende o argumento. Consequentemente, não é apropriado dizer que a filosofia é o que ama o 
saber, pois devemos mensurar como se ama o saber, e pensar nas modalidades dessa acepção. A resposta anterior fomenta a criação ideal de modelos e metas para se "chegar" ao saber (MASCARO, 2019a).

Conclui-se que a filosofia é, como afirma Mascaro (2019a) o que dizerem o que a filosofia seja. Um desenho explícito sobre isso, é que Sócrates foi um filósofo para uns e não para outros, mas o que realmente demarcou se ele foi ou não filósofo, foi a tradição.

A filosofia se assenta na tradição, é um critério, um saber que vai se acumulando, e com o tempo, tem-se um rol de filósofos/as ou cânones. Esse rol é variável e está em constante disputa. Uma demonstração disso é que existem acepções laicas contra acepções teológicas, ou conservadora em contraponto a revolucionária. $\mathrm{Na}$ historicidade do pensamento filosófico grego, Sócrates era considerado um filósofo pagão para a Idade Média. Na modernidade, a ligação de quem era ou não filósofo/a estava relacionado com os ideários burgueses (MASCARO, 2019a). A lista de filósofos/as tem que ser colocada em interrogação, portanto, questiona-se: filósofos/as para quem?

Discute-se ainda sobre a filosofia e os seus métodos. Platão e Marx possuem modelos diferentes de pensamentos, as caminhadas dos seus saberes filosóficos são distintas, até por viverem em relações sociais diferentes, a Idade Antiga de Platão era caracterizada pelo escavismo, e a Idade Contemporânea de Marx está situada no modo de produção capitalista. O objeto e tema de cada filosofia também são diferentes, a depender do cenário histórico, a exemplo de que na antiguidade, a natureza era centralizada no debate filosófico, já o medievo não centraliza a natureza, pensa a divindade, por esses processos históricos, mudam-se os métodos, conteúdos e temas (MASCARO, 2019a).

A filosofia é um pensamento sistemático, radical e pleno. Procura o sentido da sociedade, e não as estatísticas e movimentos empíricos dela, como faz a sociologia. Entre os métodos, há o analítico, que forma o pensamento filosófico pelos textos do/a filósofo/a, e o método estrutural, caracterizado pela lógica interna do pensamento filosófico, ou seja, a estrutura. As singularidades de cada jusfilosofia deve ser respeitada para que se mantenha vivo cada elemento dela (MASCARO, 2019a).

A filosofia possui uma dupla estrutura: uma é a tradição histórica sistematizada, e a outra são as condições do mundo, pois como afirma Mascaro (2019a, p. 4), "a filosofia é a extração mais radical e profunda do pensamento humano a respeito de si e do mundo". Uma jusfilosofia positivista, por exemplo, colide com o jusnaturalismo, ou seja, a 
filosofia não é meramente um amontoado de escritos sobre um assunto, ela é um espaço onde ocorre enfrentamentos do pensamento e da realidade. Embora, a filosofia seja o estudo mais aprofundado e estruturado sobre o pensamento, ela se volta para a realidade histórica.

Conforme Mascaro (2019a, p. 5), "a filosofia é uma forma de práxis”, o qual estrutura um nexo necessário entre o pensamento e a realidade. As filosofias não são ahistóricas, neutras no processo histórico e político, elas estão situadas em um contexto social, conservando-a ou transformando-a. Pela perspectiva do jovem Marx ${ }^{\mathrm{i}}$ e Engels (2019, p. 91), vale destacar uma das Teses de Feuerbach: "Os filósofos apenas interpretaram o mundo de maneiras diferentes; o que importa, contudo, é transformá-lo". A tradição da história da filosofia está fincada na materialidade e na dialética entre a reflexão e o mundo, os modos de produção e as relações sociais determinam a jusfilosofia. Mascaro (2019a, p. 7) escreve que “[...] a grande filosofia está numa angustiante situação em face do próprio mundo e de sua história total". Mascaro (2008, p. 37) sobre o caráter transformador da filosofia, afirma que "Marx sela um destino inarredável à atividade filosófica e a seu pensamento geral: a filosofia deve servir à transformação".

Althusser (1999) diferencia a filosofia em dois aspectos, uma filosofia da resignação, sem valor crítico, submissos as ideias da classe burguesa e a dominação de classes, e que a maioria das filosofias estão representadas por essa visão, passiva à opressão. Mascaro (2019a) ao endossar isso, denuncia que “[...] a maioria média dos filósofos confirma seus tempos, e ao contrário de Sócrates, que foi morto, tais filósofos médios foram e são pagos pelos poderosos".

Por outro lado, existe a filosofia ativa ou Filosofia, com "f" maiúsculo, que empenhada em enfrentar a dominação, exerce a criticidade, a partir do seu conhecimento do mundo, com a possibilidade de transformação. Essa última filosofia, nem sempre existiu, o seu desenvolvimento se deu em sociedades marcadas pelas classes sociais, o Estado e a existência das ciências no ocidente. Althusser (1999) se refere as relações de classe, e o direito que sobredetermina a mercadoria, principalmente a utilização da formajurídica para sancionar a transição do Estado feudal ao Estado e modo de produção capitalista. Há a conjugação de acontecimentos políticos e científcos que modificaram a filosofia, desde a constituição do Império Macedônico e das descobertas biológicas em Aristóteles, e por consequinte, os reflexos disso na filosofia aristotélica até as grandes 
lutas do Movimento operário e a criação da ciência da histórica na filosofia de Marx. Portanto, o pensamento de determinado/a filósofo/a está inserido em uma conjuntura, o qual é dominada pela conjunção política-científica que vai diferenciá-la do pensamento anterior (ALTHUSSER, 1999).

A filosofia é radical, pois vai à origem ou raiz dos problemas. A filosofia é crítica, porque vai além do já dado, esclarecendo e enfrentando o mundo. A filosofia é o apontar da possibilidade, do ainda não dado, como mostra Bloch (MASCARO, 2008). A filosofia se estrutura por uma dialética entre ela mesmo e o mundo. O pensamento mais alto da filosofia é aquele que supera o já dado, e constrói possibilidades outras para a realidade do mundo, ou seja, é aquele que transforma estruturalmente a sociedade, Mascaro (2019a) lembra que:

\begin{abstract}
A filosofia, quando não só uma coleção de ideiais filosóficas bem comentadas, é o vigoroso pensamento que enfrenta orginalmente o mundo. Mas a filosofia tem um limite em face do mundo e, por seu lado, também o mundo tem um limite em face da filosofia. Há uma dialética de desconhecimentos recíprocos entre o mundo e a filosofia. $\mathrm{O}$ mundo - seu poder, sua representação e sua estrutura - é maior que o pensamento sobre o mundo, por isso a filosofia, ainda que aponte mais além, não consegue, por si só, levar o muno aos seus novos horizontes. De outro lado, o mundo é menor que a filosofia, na medida em que o mundo se reproduz de certos modos, mas seus modos não são todos inexoráveis. A filosofia, assim sendo, ao estudar o mundo e sua estrutura, pode apontar o novo. A filosofia é maior que o mundo pelo apontar da possibilidade. Se se considera por ciência o pensamento da confirmação mais severa e próxima possível da realidade do mundo, a filosofia é então um pensamento que não apenas confirma o mundo, e, em relação à ciência, nisso está a fraqueza e, acima de tudo, a grandeza da filosofia (MASCARO, 2019a, p. 7).
\end{abstract}

Villey (2008), jusfilósofo francês, embora não seja da tradição marxista, reflete sobre a diferenciação entre a filosofia e a ciência, marcadamente no fenômeno histórico da Modernidade, em que enquanto para os antigos o conhecimento estava atrelado à moralidade, ao mundo exterior e a totalidade, em contraponto, os modernos, no século XVII, por meio das ciências abstraem as coisas, criando especificações em cada ramo do saber, tornando-os específicos, particulares, separados do todo. Agora, o filósofo não reflete mais a matemática, a física, a biologia como na Grécia Antiga, o cientista produz ciência por meio do conhecimento específico e técnico de cada área, separadamente.

A modernidade como período histórico de passagem do feudalismo para o capitalismo, reverberou significativas mudanças nas relações sociais, incluindo a forma 
jurídica, ou seja, o direito que se separou da consensualidade marcada anteriormente, para a coerção e legitimação da ascensão ideológica burguesa, relacionando-se estruturalmente com a forma-mercadoria e o Estado com a finalidade de reproduzir a sociabilidade capitalista (MASCARO, 2013). Portanto, o direito como forma social tipicamente burguesa, deve ser descortinado e ultrapassado por novos horizontes revolucionários, e é uma das coisas que podem ser realizadas pela filosofia do direito. Apenas ela é insuficiente, mas os seus métodos são preciosos para traçar caminhos que rompam estruturalmente com a reprodução capitalista.

\section{O RAMO CHAMADO FILOSOFIA DO DIREITO}

Como observado, a filosofia é costurada pela tradição, e a filosofia do direito é conceituada por Mascaro (2019a) como o atrito entre a tradição da história da filosofia e o direito. A filosofia do direito é um ramo da filosofia geral, que analisa e pensa um assunto específico, o direito. A filosofia do direito é identificada como mais um ramo da filosofia geral, mas é o máximo pensamento possível sobre o tema do direito. Didaticamente, a filosofia do direito pode ser analisada como um ramo de uma árvore, no qual, a filosofia geral constitui o seu tronco e raízes, com seus diversos ramos, e um deles é a filosofia do direito.

Para Mascaro (2019a), o direito não é um fenômeno único, inalterável durante toda a história da humanidade, o direito é um fenômeno histórico. Em um determinado período, o direito estava relacionado à força, contudo, na atualidade, o direito é consensual, constituído por acordo de vontades. O passado lida mais com a filosofia do justo e no presente se fala de uma filosofia do direito. Mas no presente, a filosofia do direito ainda se ocupa da filosofia da justiça, pois a justiça ainda atravessa o direito. A filosofia do direito se estabelece pela junção de ambos, da justiça e do direito.

A filosofia do direito escapa à visão média do jurista acerca do direito, ela não se limita as respostas positivistas ou jusnaturalistas. As jusfilosofias podem refletir linhas tênues entre o direito e a política, a moral, a ética, o capitalismo, entre outras conexões (MASCARO, 2019a). Villey (2008) argumenta pelo caráter eminentemente filosófico da filosofia do direito, inseparável da tradição histórica da filosofia geral: 
[...] fizemos questão de conservar, em nossa obra, o título filosofia do direito, para sublinhar que esta disciplina não é um olhar narcíseo da arte jurídica sobre ela mesma; um palrear de velho jurista discorrendo sobre seu passado; e que ela não é apenas induzida da experiência do direito, mas é filosofia, entendendo por isso que ela busca esta visão total, ou ao menos da estrutura do todo, que afirmamos ser da alçada da filosofia (VILLEY, 2008, p. 31).

Indaga-se, $\mathrm{O}$ que é a filosofia do direito? Há uma resposta geralmente dada para o questionamento acima: de que os/as filósofos/as fazem filosofia e os/as juristas fazem filosofia do direito. Porém, essa é uma resposta inapropriada, porque o pensamento que o/a jurista faz sobre seu cotidiano, não é filosófico, é técnico e prático. O filósofo é aquele que busca refletir em saberes, ao longo do processo histórico, marcado por realidades diversas (MASCARO, 2019a).

Os/as filósofos/as do direito pensam o direito e a política, haja vista que a filosofia do direito está ao lado da filosofia política, chamada como irmã da jusfilosofia. O direito não é outro jeito de pensar, o direito é apenas mais um assunto da filosofia (MASCARO, 2019a).

Como visto anteriormente, existem métodos do saber filosófico, ou seja, o jeito de se pensar, e há assuntos que a filosofia se debruça. Um/a jurista, por exemplo, possui uma prática, o direito é um tema que a filosofia pode tratar, e não um método. A filosofia do direito pode ser uma ocupação direta ou indireta, embora de maneira indireta trate sobre o direito, com seu método pode-se pensar diretamente o direito (MASCARO, 2019a). Sartre não escreveu especificamente sobre o direito, mas seu método filosófico e escritos sobre liberdade, política e ética podem ser utilizados para uma reflexão jusfilosófica, a exemplo de Almeida (2016).

Por sua vez, Bittar \& Almeida (2019) em seus escritos conceituam a Filosofia do Direito em sentido convergente à Mascaro (2019a):

A Filosofia do Direito é um saber crítico a respeito das construções jurídicas erigidas pela Ciência do Direito e pela práxis do Direito. Mais que isso, é sua tarefa buscar os fundamentos do Direito, seja para cientificar-se de sua natureza, seja para criticar o assento sobre o qual se fundam as estruturas do raciocínio jurídico, provocando, por vezes, fissuras no edifício que por sobre as mesmas se ergue (BITTAR; ALMEIDA, 2019, p. 66). 
Na estrutura interna do pensamento, com métodos diferentes de Mascaro (2019a), o juspostivista eclético ${ }^{\mathrm{ii}}$, Reale (2002) escreve que a filosofia do direito possui duas acepções: uma lata e outra estrita. A primeira é conceituada pela função e valores das normas que governam a sociedade no sentido da justiça, portanto, a filosofia do direito seria o pensamento filosófico da realidade jurídica. A segunda acepção conceitua a filosofia do direito por um estudo metódico dos pressupostos ou condições da experiência jurídica, observando a sua unidade sistemática. É pela jusfilosofia que se estuda os pressupostos lógicos, axiológicos e históricos da experiência jurídica. Axiologia aqui entendida como valores, visto pela filosofia como teoria ou filosofia dos valores (ABBAGNANO, 2007).

O salto reflexivo que estrutura a filosofia do direito, sai da tecnicidade, transcende a mera constatação técnica da legalidade ou norma jurídica. A filosofia do direito envolve a relação estrutural entre o direito e o todo histórico e social, para além das preocupações do justo e injusto (MASCARO, 2019a). Para Bittar e Almeida (2019), a Filosofia do Direito deve envolver princípios, causas, utilidade social, necessidade, deficiências, perspectivas profundas de tal forma a provocar as estruturas científicas do fenômeno jurídico.

Diferentemente das ciências empíricas, a Filosofia do Direito trata do valor, fim, ideia, ideal do direito, o qual com o seu complemento da política jurídica, busca transformar o direito ideal em realidade. O dualismo metodológico entre o valor e realidade, ser e dever ser, através dos limites históricos determinam materialmente a ideia, para Radbruch (2002), como ilustração do raciocínio, a filosofia do direito seria uma teoria do direito justo. A ideia do direito perpassa a ideia de justiça e a sua problemática conceitual, que é chamada por Reale (2002) como juridicidade. Pensar os moldes e conjunturas socioculturais que estruturam internamente o pensamento jufilosófico é fundamental para iniciar o pensamento de uma filosofia do direito mais crítica e voltada para a justiça social.

Por sua vez, Bittar e Almeida (2019) conceituam a Filosofia do Direito como um saber crítico sobre a Ciência do Direito e a sua práxis. A fundamentação do direito dada pela filosofia pode causar rachaduras no edifício da racionalidade jurídica, assim, a 
jusfilosofia pode conservar a realidade social, querer retornar o passado ou modificar as estruturas historicamente.

Quanto a conceituação sobre a Filosofia do Direito cabe dizer que existem conceituaçõe(s), um leque de caminhos se formam para definir o que seria a jusfilosofia. É entre o direito, a filosofia e a realidade que a Filosofia do Direito pode ser compreendida por seus aspectos teóricos, fundamentos e epistemologias. Há variadas perspectivas de compreender os fenômenos jusfilosóficos, e desde a Antiguidade, houveram significativas alterações.

Em comparação as outras conceituações, a desenvolvida por Mascaro (2019a) é a mais atenta ao todo complexo estrutural do direito e o capitalismo. Por se situar na tradição marxista, o pensamento jurídico de Mascaro (2019a) representa a real possibilidade de transformação social em busca do socialismo. E a filosofia do direito possui um papel essencial nesse processo de balançar a legitimidade da forma jurídica, que deriva da forma-mercadoria, e a fundamenta. Além, de observar as relações entre o direito e a forma-política, ou seja, o Estado que encarado como neutro atua para desarticular o movimento de trabalhadores, e de reprimir qualquer tentativa de mudança social radical (MASCARO, 2013).

Mascaro (2019a) mostra nas suas obras como as filosofias do direito tiveram conexões com o sistema político econômico de cada época, portanto, não se espera que a filosofia medieval se pareça, mesmo que minimamente, com a filosofia contemporânea, ora, do feudalismo para o capitalismo atual, as singularidades de uma com a outra são notórias. Entre Platão e Marx, um da Antiguidade e outro da Contemporaneidade, há um percurso histórico-político e econômico atrás de dois pensamentos singulares. A historicidade, portanto, marca as filosofias do direito, desenhando uma linha tênue entre a Filosofia Política e a Ética nas análises filosóficas jurídicas. A Filosofia do Direito permite compreender o capitalismo como origem da tecnicidade do direito, a formação da forma jurídica, a especificação da Teoria Geral do Direito e a apatia do jurista frente às desigualdades sociais.

A Filosofia do Direito acumulou várias funções ao longo da história, como refletir o ordenamento jurídico; criticar as atitudes e atividades dos operadores do direito, questionar a aplicação das leis, os exercícios dos direitos, investigar as desestruturações e enfraquecimento dos sistemas jurídicos; depurar a linguagem jurídica; abalar conceitos 
arcaicos desenraizados da concretude da sociedade, desmascarar as ideologias que controlam o mundo jurídico, promover a cultura do humanismo, ética e filosoficamente contra a alienação, tecnificação, pragmatismo do direito; abarcar pensamentos sobre a justiça, a ética, aportes críticos da legalidade e a construção de filosofias atentas à realidade social do mundo capitalista, entre outras (BITTAR; ALMEIDA, 2019).

A filosofia do direito não se confunde com a Teoria Geral do Direito, essa é a teorização sobre todos os ramos dogmáticos jurídicos, como o direito constitucional, civil, penal, trabalhista etc. A Teoria Geral do Direito, também chamada de Teoria Geral das Técnicas jurídicas ou Teoria Geral da Tecnologia Jurídica, se ocupa com a validade e eficácia da norma jurídica. A matéria ou disciplina da Teoria Geral do Direito é a Introdução do Estudo do Direito. Ela é a totalização dos saberes, práticas do direito já dados (MASCARO, 2019a; 2019b).

Com o capitalismo, advindo da Idade Moderna, o direito começa a possuir especificidade técnica, vista como um conjunto de normas impostas pelo Estado, tem-se a Teoria Geral do Direito. A Filosofia do Direito é mais alta que a Teoria Geral do Direito, pois a filosofia problematiza os ramos dogmáticos jurídicos. A filosofia do direito questiona: Para que e quem servem as normas jurídicas? As normas dominam a sociedade? São aplicadas de modo justo ou injusto? Para qual classe? Qual sua natureza concreta, material? (MASCARO, 2019a).

A filosofia do direito indaga a natureza histórica e social do direito, é a mais profunda e crítica do direito. A filosofia é profundamente crítica, um incômodo que choca a estrutura jurídica. Conclui-se que a filosofia do direito é o pensamento filosófico sobre o assunto jurídico, que transcende a prática do direito, indaga sobre a realidade já dada e alimenta a Teoria Geral do Direito (MASCARO, 2019a).

Um pensamento de juristas ou de filósofos/as? É o/a jurista filósofo/a que se debruça sobre a filosofia do direito, embora o método de pensamento seja oriundo da história da filosofia. Um/a filósofo/a geral geralmente não compreende com profundidade o jurídico, e o jurista quase sempre não entende a sistemática da filosofia. Isso faz com que a filosofia do direito alimente uma dúplice exigência: o/a jurista filósofo/a deve compreender de forma conjunta e profunda o direito e a filosofia. O/a filósofo/a do direito pleno é aquele/a que pensa para além do seu tempo, que procura o não dado, que visualiza 
o/a que o jurista médio não percebe. O/a jurista filósofo/a pleno enfrenta o direito e a sociedade (MASCARO, 2019a).

A filosofia do direito é a mais alta verdade jurídica sobre o direito, como lembra Mascaro (2019a, p. 14): “os fios escondidos do direito muitas vezes o determinam mais que suas camadas visíveis aos olhos do jurista". Cabe à filosofia do direito desvendar os fios escondidos do mundo jurídico, que o/a operador/a do direito ou mero/a técnico/a jurídico não consegue visualizar. Em vista disso, a filosofia do direito se ocupa com o caráter justo e injusto do direito e do mundo, a filosofia se ocupa da totalidade interna das técnicas jurídicas (MASCARO, 2019a).

O marxismo é entendido para ele, como o pensamento mais alto sobre o direito, de análise mais profunda sobre a estrutura jurídica, que por meio das relações políticas e sociais, traz à tona a racionalidade capitalista. Para Mascaro (2019a):

Somente o conjunto de leituras jusfilosóficas críticas, assentadas nas descobertas científicas de Marx, dá conta de entender o direito como fenômeno social específico, cuja forma social, derivada da formamercadoria, é necessária para a própria estruturação das relações de compra e venda da força de trabalho, garantindo, por meio do vínculo contratual, a exploração e apropriação privada. [...] Toda a realidade jurídica, então, é capitalista (MASCARO, 2018, p. 62).

A filosofia geral possui uma tradição histórica sistematizada de reflexões, com métodos próprios, o texto filosófico deve ser respeitado pela filosofia do direito. A filosofia é uma forma de práxis, o qual possui um nexo entre o pensar e a realidade, configura-se o atrito da filosofia com a realidade, podendo conservá-la ou transformá-la (MASCARO, 2019a). O marxismo é para Mascaro um pensamento diferenciado das outras filosofias, pois é com Marx que o pensamento se orienta para a transformação, através da ação revolucionária. A função da filosofia é não apenas de interpretar o mundo, mas de transformá-lo, eis o pensamento marxista inaugurando uma compreensão para além do já dado, permitindo imaginar e construir outros horizontes. Como afirma a filosofia de Bloch, a filosofia deve olhar para aquilo que ainda não há, ou seja, para a possibilidade de caminhos de enfrentamento às injustiças e desigualdades sociais (MASCARO, 2008). 
O jurista só terá chance de ser autêntico duas vezes: quando no futuro, de fato, o direito for convertido em arte, ou seja, quando o capitalismo e suas formas sociais e jurídicas forem superados e em seu lugar a sociedade, fraterna e socialista, puder julgar a cada situação e a cada coisa de acordo com sua justeza, ou então, atualmente, quando o jurista se engajar na luta pela transformação do mundo capitalista num mundo fraterno e socialista. Esta última hipótese revolucionária é, no presente, a única possível que nos resta em prol de nossa autenticidade (MASCARO, 2019b, p. 34).

A filosofia do direito de Mascaro (2019a) é reconhecida internacionalmente como expoente da filosofia marxista brasileira. Mascaro (2019a) foge e enfrenta a visão média do operador do direito, analisa o impacto que o direito leva com a modernidade, raiz da especificidade técnica e da Teoria Geral do Direito. Com a filosofia do direito em Mascaro (2019a) tem-se um salto reflexivo, pois transcende a racionalidade técnica. O direito possui um aspecto interno, que é o afazer dos juristas, porém se manifesta socialmente por meio das estruturas e relações sociais. Consequentemente, o pensamento de Mascaro (2019a) sintetiza o aprofundamento da reflexão jurídica, que intermediado pelo marxismo, sua filosofia do direito significa enfrentar o já dado no direito e na sociedade, e a busca pelo que ainda não existe, a igualdade e justiça plena. Mascaro saí do "cansaço teórico", parafraseando o filósofo Bloch, na luta pela transformação da sociedade (MASCARO, 2008).

A perspectiva crítica de Mascaro possui um aprofundamento de análise filosófica jurídica, seus estudos representam o anseio pela mudança da sociedade e a diminuição das desigualdades, atribuindo um sentido revolucionário ao filósofo do direito. Pensar sobre a filosofia, a filosofia do direito e sua história pela perspectiva da Filosofia Crítica do Direito diante da realidade do capitalismo, é construir outras possibilidades de pensamentos jurídicos que estejam engajados na transformação social em busca da utopia pelo socialismo, pois como destaca Mascaro (2019a, p. 17): “O estudo da filosofia do direito começa como história da filosofia do direito, mas não se esgota em tal, porque arranca do ser histórico e social suas possibilidades ainda não dadas”.

\section{CONSIDERAÇÕES FINAIS}

O artigo elucidou o conceito de filosofia e o tema filosofia do direito pelos escritos de Mascaro (2019a). Percebeu-se que a filosofia possui várias conceituações, a 
depender da sua história e os efeitos políticos do seu pensamento. O rol de filósofos reconhecidos como canônes é assentado na tradição histórica, embora o poder para reconhecer, propagar, censurar ou perseguir determinado pensamento filosófico estivesse/esteja concentrado na hegemonia das classes dominantes. A filosofia sempre possuiu relação com o modo de produção de cada época, desde a antiguidade com o escravismo e a contemporaneidade com o capitalismo, assim, os atravessamentos da filosofia com a materialidade social foram expostos no presente trabalho.

Diante de tal contexto, a filosofia pode apontar o ainda não dado, uma esperança para dias mais igualitários, ela está entre manter a dominação ou agir contra a desigualdade. De igual maneira, a filosofia do direito também se encontra em tal contradição, entre legitimar a forma jurídica, protetora da propriedade privada, mercantilizadora da vida e aparelho repressor e ideológico do Estado ou desestruturá-la, questionando a igualdade formal e as suas categorias liberais, como sujeito de direitos, cidadãos, iludindo os indíviduos com direitos minímos civilizatórios.

No texto foi demonstrado que o direito é mais um tema da filosofia geral, como um ramo de uma grande árvore. A filosofia do direito foi conceituada como atrito entre a tradição histórica da filosofia geral e o direito, ela é o pensamento mais alto sobre o jurídico e que alimenta a Teoria Geral do Direito. Ademais, a filosofia do direito traça ligações do jurídico com a ética, moral, e a própria relação social capitalista.

Portanto, o artigo elucidou conceitos chaves para que possam surgir outras reflexões jusfilosóficas, partindo da tradição marxista, para pensar, estruturalmente, a subjetividade jurídica. Um dos caminhos a serem estudados para aprofundar a criticidade do pensamento de Mascaro (2019a) é a história da filosofia do direito, pois o direito é um fato tipicamente burguês e moderno, e os três caminhos ou matrizes apontados como jusfilosofias na contemporaneidade: os juspositivismos, o não juspositivismo/decisionismo/existencialismo e o marxismo. Este último é o pensamento mais avançado sobre o direito, e que é colhido por diversas pesquisas tecidas pelas ideias revolucionárias de Mascaro (2008; 2013; 2018; 2019a; 2019b). Com Mascaro (2008; 2013; 2018; 2019a; 2019b), a filosofia do direito se tornou uma ferramenta incontornável de luta política contra a forma jurídica e a socialibilidade capitalista, além da busca pela transformação social pelo socialismo. 


\section{REFERÊNCIAS BIBLIOGRÁFICAS}

ABBAGNANO, N. Dicionário de filosofia. 5. ed. São Paulo: Martins Fontes, 2007.

ALMEIDA, S. L. de. Sartre: Direito e Política: Ontologia, liberdade e revolução. São Paulo: Boitempo, 2016.

ALTHUSSER, L. Sobre a reprodução. Trad. Guilherme João de Freitas Teixeira. Petrópolis: Vozes, 1999.

BITTAR, E. C. B.; ALMEIDA, G. A. de. Curso de Filosofia do Direito. 14. ed. São Paulo: Atlas, 2019.

CHAUI, M. Convite à Filosofia. São Paulo: Editora Ática S.A, 2011.

MARX, K.; ENGELS, F.. A ideologia alemã: crítica da mais recente filosofia alemã em seus representantes Feuerbach, B. Bauer e Stirner. Trad. Milton Camargo Mota. Petrópolis: Vozes, 2019.

MASCARO, A. L. Crise e golpe. São Paulo: Boitempo, 2018.

MASCARO, A. L. Estado e forma política. São Paulo: Boitempo, 2013.

MASCARO, A. L. Filosofia do Direito. 7. ed. São Paulo: Atlas, 2019a.

MASCARO, A. L. Introdução ao estudo do direito. 6. ed. São Paulo: Atlas, 2019b.

MASCARO, A. L. Utopia e Direito: Ernst Bloch e a Ontologia Jurídica da Utopia. São Paulo: Quartier Latin, 2008.

RADBRUCH, G. Introdução à Filosofia do Direito. Trad. Prof. Jacy de Souza Mendonça. São Paulo: Martins Fontes, 2002.

REALE, M. Filosofia do Direito. 20. ed. São Paulo: Saraiva, 2002.

VILLEY, M. Filosofia do direito: definições e fins do direito: os meios do direito. Trad. Márcia Valéria Martinez de Aguiar. 2. ed. São Paulo: Martins Fontes, 2008.

\footnotetext{
${ }^{\text {i }}$ Utilizando a divisão feita por Althusser (1999) sobre o que ele chamou de corte epistemológico entre o pensamento de Marx, a expressão jovem Marx se refere ao período das obras de Marx que ainda utiliza algumas categorias burguesas, chamado como período ideológico, diferentemente do Marx de maturidade ou período científico, que rompe profundamente com Hegel e estrutura uma análise político-econômica do modo de produção capitalista. A obra que situa o corte, é A ideologia alemã de 1845, e o livro que melhor representa o segundo período posterior a 1845, é O capital (MASCARO, 2019a).

${ }^{i i} \mathrm{O}$ juspositivismo eclético é a corrente positivista iniciada no século XIX com a Escola histórica do direito, os juristas defendiam que a técnica normativa estatal deveria ter um fundamento social e histórico. Os intitutos sociais, como a família, propriedade etc, criaram conceitos jurídicos, não estando a sua origem na lei ou Estado, mas sim no povo. Concepção distinta do juspositivismo estrito, representado por Kelsen, em que o direito é reduzido a norma jurídica produzida pelo Estado (MASCARO, 2019a).
} 